\title{
Weighting the Recursive Spectral Bisection Algorithm for Unstructured Grids
}

\author{
Darryl Allen \\ Evi Dube \\ Garry Rodrigue
}

This paper was prepared for submittal to the

7th SIAM Conference on Parallel Processing for Scientific Computing San Francisco, $C A$

February 14-18, 1995

September 1994

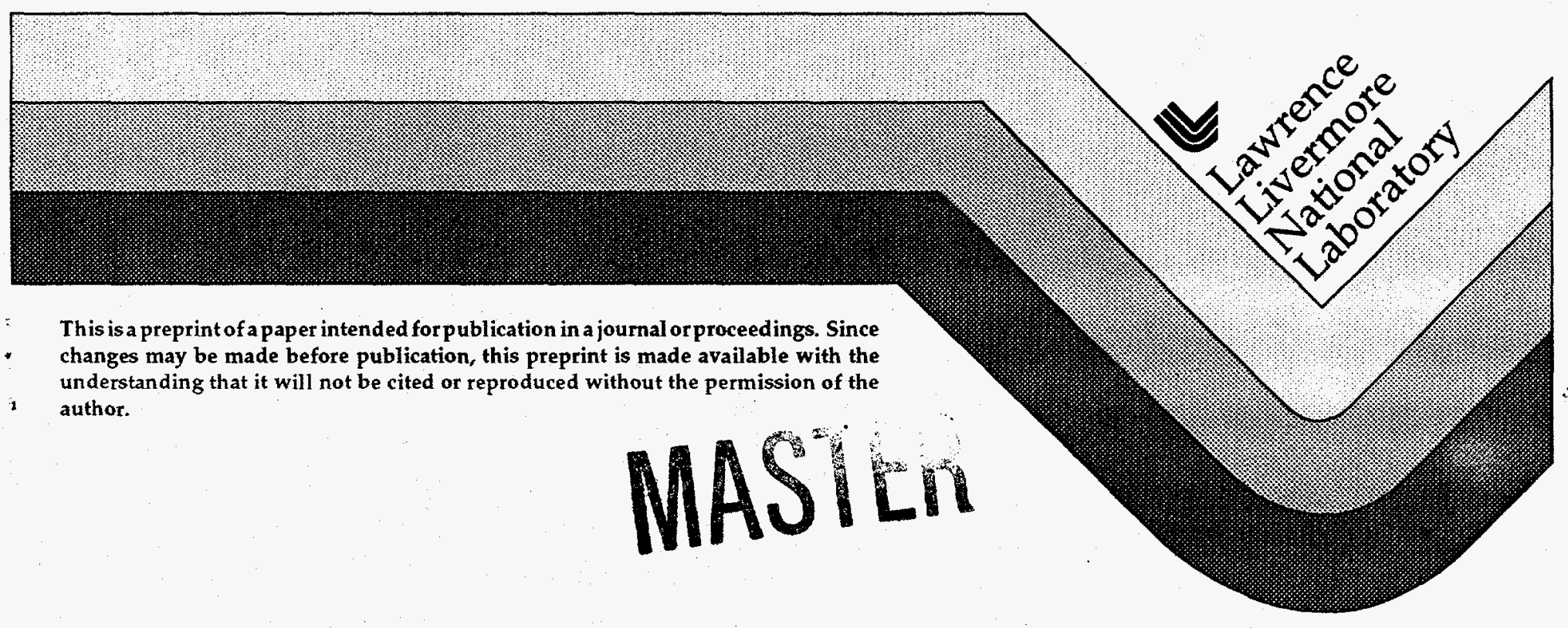


DISCLAIMER

This document was prepared as an account of work sponsored by an agency of the United States Government. Neither the United States Government nor the University of California nor any of their employees, makes any warranty, express or implied, or assumes any legal liability or responsibility for the accuracy, completeness, or usefulness of any information, apparatus, product, or process disclosed, or represents that its use would not infringe privately owned rights. Reference herein to any specific commercial products, process, or service by trade name, trademark, manufacturer, or otherwise, does not necessarily constitute or imply its endorsement, recommendation, or favoring by the United States Government or the University of California. The views and opinions of authors expressed herein do not necessarily state or reflect those of the United States Government or the University of California, and shall not be used for advertising or product endorsement purposes. 


\section{DISCLAIMER}

Portions of this document may be illegible in electronic image products. Images are produced from the best available original document. 


\title{
Weighting the Recursive Spectral Bisection Algorithm for Unstructured Grids *
}

\author{
Darryl Allen ${ }^{\dagger} \quad$ Evi Dube ${ }^{\ddagger} \quad$ Garry Rodrigue ${ }^{\S}$
}

\section{The RSB Algorithm}

When solving partial differential equations numerically on parallel computers it is desirable to decompose the domain on which we are solving the equations in such a way as to equalize the workload among the processors while minimizing the communication between them. This is equivalent to finding a partition of the graph representing the calculation into equal subgraphs cutting as few edges as possible. One such algorithm in use is the recursive spectral bisection algorithm (RSB), [2]:

1. Generate the Laplace matrix for the graph representing the dependencies between the calculation taking place at each vertex of the graph.

2. Compute the eigenvector corresponding to the smallest non-zero eigenvalue, called the Fiedler vector.

3. Sort the vertices according to size of entries in the Fiedler vector.

4. Assign half the vertices into each subgraph.

This algorithm can be shown to arise from rounding to feasibility the solution to relaxation of the following nonlinear combinatorial optimization problem:

*This work was performed under the auspices of the U.S. Dept. of Energy by Lawrence Livermore National Laboratory under contract No. W-7405-Eng-48

Dept. of Applied Science, University of California, Davis, Calif. and Lawrence Livermore National Laboratory, Livermore, Calif., 94550, e-mail: gordon@wente.llnl.gov, Ph: 510-4230345, FAX : 510-422-8681

'Lawrence Livermore National Laboratory, Livermore, Calif., 94550, e-mail: dube1@llnl.gov, $\mathrm{Ph}$ : 510-423-6021

${ }^{\S}$ Dept. of Applied Science, University of California , Davis, Calif. and Lawrence Livermore National Laboratory, Livermore, Calif., 94550, e-mail: rodrigue@llnl.gov, Ph: 510-422-4037, FAX : 510-422-8681 


$$
\begin{aligned}
\text { Minimize } f(x) & =x^{t} L x \\
\text { Subject to } x^{t} e & =0 \\
x_{i} & \in\{-1,1\}
\end{aligned}
$$

where $L$ is the Laplacian matrix of the graph. The objective function counts the number of edges cut by the partition by a vector $x$.

\section{Weighting the RSB Algorithm}

It can be the case however that the partition generated by the RSB does not have some desired feature. This can arise for example when modeling numerically the boundaries between dissimilar materials. In this context it might be desirable that all calculations at this boundary take place on one processor. We extend the RSB algorithm to handle those cases. The first extension involves modifying the the graph so as to influence the outcome of the RSB algorithm. This can be done by artificially creating "supernodes" or by artificially increasing the edge connectivity in the desired region. Another extension is to modify the RSB algorithm to provide for the weighting of edges, [1]. This algorithm minimizes the total cost of edges cut by a partition rather than minimizing the number of edges cut as is done in the RSB algorithm.

Each of these extensions is implemented and applied to a 3-dimensional unstructured grid problem that arises in the finite element solution of an applied mechanics problem.

\section{References}

[1] Hendrickson,B. and Leland, R., The Chaco User's Guide, Version 1.0, Sandia Report SAND93-2339, Oct., 1993

[2] Simon, H., Partitioning of Unstructured Problems for Parallel Processing, Computing Systems in Engineering, Vol. 2, No. 2/3, pp. 135-148, 1991. 